\title{
UM LEVANTAMENTO DE COLOCADOS COM USO DAS FERRAMENTAS DA LINGUÍSTICA DE CORPUS: UM ESTUDO DE COMBINAÇÕES LEXICAIS RELACIONADAS A SERVIÇOS E ESTRUTURAS OFERECIDOS DENTRO DA REDE HOTELEIRA MUNDIAL
}

\section{A Collection of Collocates Produced through Corpus Linguistics Tools: a study on combinations of lexical items related to services and facilities offered by International Hotel chains}

\begin{abstract}
RESUMO: $O$ trabalho teve por objetivo fazer levantamento e estudo de vocabulário da área de hotelaria envolvendo especificamente serviços e instalações em hotéis 4 e 5 estrelas. Os achados da pesquisa visam contribuir com a ampliação de conhecimentos de professores e alunos da Faculdade de Tecnologia de São Paulo envolvidos com o curso de Gestão de Turismo. Para realização da pesquisa, utilizamos a ferramenta eletrônica AntConc 3.2.4w para seleção e estudo de termos e colocados. Destacamos as palavras-chave com presença estatisticamente expressiva no corpus e os colocados mais frequentes. Os resultados mostraram algumas combinações lexicais comuns dentro dos materiais didáticos utilizados na instituição, outras combinações, porém, são inusitadas.
\end{abstract}

Palavras-chave: Hotelaria; Língua inglesa; Vocabulário especializado

\begin{abstract}
The work aimed to collect and study vocabulary in the hotel business area involving specifically services and facilities in four and five star hotels. The findings of the research are intended to enhance the knowledge of teachers and students at the Technology College of São Paulo involved with the Tourism Management course. To carry out the research, we utilized the electronic tool AntConc 3.2.4w for the selection and study of words and collocates. We selected expressively present key-words in the corpus and the most frequent collocates. The results showed some lexical combinations present in the tourism teaching materials employed in the institution, but some combinations are totally new.
\end{abstract}

KEYWORDS: Hotel business; English language; Specialized vocabulary 


\section{Introdução}

O potencial do Brasil em turismo e hotelaria é evidente. Essas áreas desempenham papel destacado na economia do país, mas dependem de políticas favoráveis e investimentos bem direcionados para que todos usufruam dos benefícios sociais e econômicos que podem proporcionar Carvalho (2000). Na verdade, carecemos de iniciativas conjuntas que envolvem necessariamente o setor público, o governo, e diferentes setores privados relacionados de alguma forma às áreas em questão. Outra parte que poderá desempenhar papel importante é aquela representada pelas instituições de pesquisa e ensino Imbernón (2009). Acredito que cabe a elas serem centros de excelência para o desenvolvimento de novos conhecimentos abrangendo não somente as áreas citadas, mas também as áreas que envolvem comunicação, quadro em que figura com grande destaque a língua inglesa. Quanto mais entendermos diferentes culturas, mais facilmente nós seremos integrados ao complexo mundo globalizado em que hoje vivemos, dentro do qual a atividade do turismo desempenha importante papel.

Os materiais didáticos adotados na Faculdade de Tecnologia de São Paulo procuram contemplar as necessidades da área de turismo visando a inserção dos alunos no mercado de trabalho; promovem a interação dos aprendizes em situações de comunicação pertinentes ao seu ramo de atividade. Porém, para que se garanta compatibilidade com as exigências do mercado, são importantes evidências empíricas: pesquisas que permitam um levantamento da linguagem autêntica presente nos textos Berber Sardinha (2011). A proposta poderá contribuir com a produção de novos conhecimentos sobre a linguagem hoteleira e suas formas de propaganda, representando um modelo alternativo de consulta, pesquisa e aprendizagem do idioma (Conrad, Dusicka, Pfeiffer (2009).

O objetivo deste trabalho é desenvolver um banco de dados com textos da área de hotelaria destacando vocabulário relacionado à estrutura (instalações) e serviços oferecidos por hotéis internacionais presentes em diferentes regiões do mundo. Com base no corpus, extrair palavras-chave (substantivos) e levantar as combinações lexicais, os adjetivos a eles relacionados. Complementarmente, fazer estudo comparativo entre as diferentes áreas selecionadas na coleta, utilizando como critério a frequência das palavras-chave presentes nos textos. Finalmente, disponibilizar o material para a comunidade de usuários da Faculdade de Tecnologia de São Paulo, professores e alunos interessados na pesquisa.

As palavras-chave e as diferentes combinações lexicais poderão ser utilizadas para consulta, estudo e aplicação em aulas de língua inglesa na instituição. Para utilização em aulas dentro do curso de Gestão de Turismo, os professores pesquisadores poderão optar pelos exemplos mais significativos e pertinentes aos objetivos das aulas. Berber Sardinha (2011:309). As combinações lexicais poderão ser pesquisadas em contextos mais amplos 
com acesso às linhas de concordância levantadas a partir dos textos do banco de dados, com utilização da ferramenta eletrônica AntConc 3.2.4w, com acesso aos grandes corpora, como o BNC (British National Corpus), o COCA (Corpus of Contemporary American English) em http://corpus.byu.edu e com acesso a sites da área na própria rede.

Iniciamos o artigo com breve introdução sobre a linguística de corpus, a seguir apresentamos a coleta e a seleção de textos base para a pesquisa, em seguida destacamos a metodologia para o desenvolvimento do trabalho e a discussão dos dados; finalmente, as conclusões.

\section{A linguística de corpus e a linguagem autêntica}

O'keefe \& McCarthy (2010) destacam a organização dos primeiros corpora, os procedimentos de coleta utilizados e os estudos de léxico, o que nos remete a épocas remotas na história. Os primeiros registros, segundo os autores, nos fazem viajar séculos no tempo, pois envolvem trabalhos em literatura antiga e a própria Bíblia. Um exemplo disso é o trabalho do jesuíta Roberto Busa que, na década de 1950, fez compilações da extensa obra de Tomás de Aquino.

\section{Segundo Berber Sardinha,}

A linguística de corpus ocupa-se da coleta e da exploração de corpora, ou conjuntos de dados linguísticos textuais coletados criteriosamente, com o propósito de servirem para a pesquisa de uma língua ou variedade linguística. Como tal, dedica-se à exploração da linguagem por meio de evidências empíricas, extraídas por computador. (SARDINHA, 2004, p.3)

Ainda segundo o autor, outro elemento central da conceituação em que a Linguística de Corpus se baseia é a visão probabilística da linguagem. A visão da linguagem como sistema probabilístico pressupõe que, embora muitos traços linguísticos sejam possíveis teoricamente, não ocorrem com a mesma frequência.

$\mathrm{O}$ autor ressalta ainda que uma teoria da linguagem deve incorporar a probabilidade de ocorrência dos traços além da possibilidade teórica de ocorrência baseada na intuição ou introspecção do falante nativo. Afirma:

Para saber qual a probabilidade de um traço ou estrutura é necessária, portanto, a observação empírica da frequência do emprego realizado por diversos usuários em contextos definidos. (SARDINHA, 2004:31$32)$. 


\subsection{A importância do léxico no contexto da Linguística de Corpus}

Essa discussão estimula reflexão e ação sobre as possibilidades da Linguística de Corpus e suas ferramentas na medida em que nos coloca em contato com a linguagem autêntica, com o texto propriamente dito. Permite-nos vislumbrar uma luz no final do túnel e soluções para as questões mais complicadas envolvendo a léxico-gramática, bem como seu uso nas diferentes situações de comunicação das quais somos cotidianamente ativos participantes. As linhas de concordância e a utilização dos grandes corpora são elementos de grande importância para o desenvolvimento de nosso trabalho, em especial para pesquisa e atividades de ensino. A visão dos autores, abordada a seguir, contribuiu grandemente para a execução do trabalho, como se procurará demonstrar.

Tribble (2010) define concordância, citando Sinclair: "A concordance is a collection of the occurrences of a word-form, each in its own textual environment, in its simplest form, it is an index." Sinclair (1991:32). Segundo ele, a definição de Sinclair é muito importante porque nos lembra dos tempos em que os levantamentos de léxico eram feitos manualmente, o que sem dúvida, reforça a ideia da importância do computador e o papel que tem na coleta e análise de dados, especialmente no tocante às concordâncias e aos colocados, combinações envolvendo em especial substantivos com adjetivos. Eles nos permitem acesso às diversas combinações lexicais presentes na língua. As palavraschave, por sua vez, possibilitam acesso a palavras importantes nos textos, importantes por apresentarem frequência estatística diferente no corpus de estudo e no corpus de referência. O corpus de referência é um corpus geral, maior que funciona como termo de comparação para análise; fornece uma norma com a qual se faz a comparação das frequências do corpus de estudo (SARDINHA, 2004, p.96-97). Berber Sardinha define corpus (palavra de origem latina que tem como forma plural corpora) como: "Uma coletânea de textos naturais, escolhidos para caracterizar um estado ou variedade de linguagem" (SARDINHA, 2004).

A pesquisa poderá contribuir com a ampliação de conhecimentos dos professores da área de Turismo sobre as particularidades léxico-gramaticais presentes na língua inglesa em textos de propaganda hoteleira, instrumentalizando-os academicamente e profissionalmente na área em que atuam e estimular a pesquisa no ambiente da instituição.

\section{Seleção de textos}

Optamos pela internet para efetuarmos a coleta do material necessário para a pesquisa pela abrangência e a facilidade de acesso às informações. Selecionamos 160 textos de sites presentes na rede que veiculavam informações sobre hotéis 4 e 5 estrelas em diferentes partes do mundo. A coleta abrangeu 8 áreas distintas, ou seja, Oceania, Ásia, África/Oriente Médio, Europa Oriental, Europa Ocidental, América do Norte, América Central e América do Sul. Cada uma das 8 áreas contou com 20 textos relacionados aos continentes citados com destaque para países regularmente visitados. $\mathrm{O}$ 
corpus total conta com 101.425 palavras e foi formado com levantamento feito na área dos sites que informam sobre services e facilities dos hotéis. Os países não incluídos nessa fase da pesquisa deverão fazer parte de seleções futuras pelo fato de a coleta ser um processo permanente. Por exemplo, na Europa ocidental, priorizamos países muito procurados para o turismo como o Reino Unido, a França, a Alemanha, a Itália e a Espanha; demos o mesmo tratamento às outras áreas estudadas. Como mencionado na seção "objetivos" os substantivos relacionados à estrutura e aos serviços oferecidos pelos hotéis e os adjetivos relacionados a eles são o objeto de estudo.

Os textos da rede são fonte importante de estudo constituindo em elemento essencial para o desenvolvimento desta pesquisa. Segundo Berber Sardinha,

[....] com a abundância de arquivos em formato digital em rede, os praticantes da Linguística de Corpus não precisam mais, em muitos casos, esperar para que terceiros criem e disponibilizem corpora. Pelo contrário, eles mesmos podem criar seus próprios corpora para seus propósitos. Isso é positivo visto que o cenário dos gêneros digitais modifica-se rapidamente, sempre atrelado ao desenvolvimento de novas tecnologias e à melhoria da infraestrutura de transmissão de dados. (SARDINHA, 2011, p.327).

\section{Metodologia}

Para cumprirmos os objetivos estabelecidos para a pesquisa, observamos os seguintes passos: fizemos levantamento de hotéis principalmente 4 e 5 estrelas de diferentes nacionalidades em sites de propaganda presentes na rede; o material foi utilizado para a composição de um banco de dados que deverá ser renovado ou ampliado periodicamente. Em seguida, acessamos as informações disponíveis sobre os hotéis destacados, em especial, textos de propaganda e informações gerais sobre a estrutura, as instalações (facilities) e os serviços por eles oferecidos. Concluída essa fase, selecionamos os textos que foram salvos em txt, (texto sem formatação) forma que permite estudo linguístico adequado. Finalmente, com utilização da ferramenta eletrônica de análise linguística, o AntConc 3.2.4w fizemos levantamento e estudo do léxico presente nos textos. Elaboramos listas de palavras e palavras-chave por frequência do corpus total e posteriormente das diferentes áreas, considerando os substantivos (palavras-chave) relacionados à estrutura e aos serviços oferecidos pelos hotéis. Fizemos complementarmente levantamento das palavras-chave e das combinações lexicais presentes no corpus total e nos corpora de diferentes áreas. O corpus e as combinações lexicais selecionadas serão mantidos em um banco de dados para consulta e estudo dos professores e alunos da área e realimentado periodicamente como citado acima. O corpus de estudo contou com 160 textos e 101.425 palavras, o corpus de referência é o BNC, o British National Corpus-World com 110.691.482 palavras. Para a definição do corpus, adotamos a abordagem impressionística, que considera um corpus de estudo contendo 
entre 20 mil e 200 mil palavras, um corpus pequeno, porém representativo para o fim a que se propõe Aston (1997).

\subsection{Números gerais - word tokens e word types por área pesquisada.}

\begin{tabular}{|l|l|l|}
\hline Região/Continente & Word tokens & Word types \\
\hline Oceania & 12.715 & 2.959 \\
\hline África/Oriente Médio & 20.594 & 4.062 \\
\hline Ásia & 13.399 & 3.323 \\
\hline Europa Oriental & 13.797 & 3.017 \\
\hline Europa Ocidental & 10.434 & 2.576 \\
\hline América do Norte & 10.779 & 2.797 \\
\hline América Central & 8.799 & 2.466 \\
\hline América do Sul & 10.908 & 2.846 \\
\hline
\end{tabular}

\section{Resultados e discussão}

Apresentamos inicialmente uma lista com 20 palavras-chave de alta frequência presentes no corpus total, abrangendo todas as áreas, 10 palavras relacionadas à estrutura e 10 palavras relacionadas a serviços. Em seguida, uma lista com 10 palavras de alta frequência presentes em cada área estudada, 5 palavras relacionadas à estrutura e 5 palavras relacionadas a serviços por área. Finalmente, selecionamos para estudo, 4 palavras-chave do corpus total, 2 palavras relacionadas à estrutura e 2 palavras relacionadas a serviços e seus colocados e 2 palavras-chave de diferentes corpora, 1 palavra relacionada à estrutura e 1 palavra relacionada a serviços e seus colocados (substantivos, adjetivos e particípios passados). Os achados da pesquisa são apresentados e discutidos a seguir. Destacamos aqui marcas estatísticas e o sentido das combinações lexicais nos diferentes contextos em que são utilizadas.

Observamos nessa sequência palavras relacionadas à estrutura, predominância de léxico relacionado aos aposentos propriamente ditos, ou seja, rooms e suítes, palavras com grande destaque. Porém, chama atenção a presença de quatro palavras sem qualquer relação com acomodação. Trata-se de spa, pool, courts e equipment. A presença de palavras relacionadas a esse tipo de estrutura pode indicar uma valorização das áreas de 
saúde e lazer dentro dos hotéis. A área da gastronomia é contemplada na sequência com expressiva presença das palavras restaurant e bar; bathroom e terrace vem em seguida com presença menos expressiva no corpus em relação às anteriores.

Observamos nessa sequência palavras relacionadas a serviços, predominância de léxico relacionado à cozinha com presença significativa das palavras dining, banquets, cuisine e breakfast na última posição, porém com um número também elevado de ocorrências. Possivelmente, a área culinária receba destaque pelo fato de o levantamento envolver hotéis de nível internacional. A palavra banquets em especial, expressa formalidade, requinte; cuisine, por sua vez, destaca as especificidades de uma região. Em segundo plano, mas também de forma expressiva aparecem as palavras fitness, treatments, massage, sauna e bath, todas ligadas à área de saúde e lazer. Porém, o grande destaque refere-se à palavra internet, um recurso tecnológico presente em todos os espaços hoje, nos lares, nas empresas e também nos hotéis de luxo como podemos observar. Em meio aos benefícios oferecidos pela indústria hoteleira, desponta a indispensável ferramenta eletrônica, o computador e a rede.

Observamos nessa sequência em palavras-chave relativas à estrutura hoteleira, a presença expressiva da palavra room e sua forma plural rooms, o que confirma o resultado observado no levantamento global. O que chama atenção é a presença da palavra spa com número de ocorrências superior a room(s) em duas regiões, em África/Oriente Médio e Ásia. Curiosamente, a palavra não aparece na área correspondente à América Central. Nas outras áreas, ela aparece sempre em segundo lugar, logo após $\operatorname{room}(s)$. A palavra pool, juntamente com spa, apresenta alta frequência, elevado número de ocorrências, confirmando também os números do levantamento global. O resultado gera uma reflexão: por que há a valorização da área de saúde na rede hoteleira em todas as regiões estudadas, exceto em uma, na América Central? Fica a questão para um debate ou novas pesquisas que possam elucidar a ocorrência. A palavra suite e sua forma suites vem a seguir com frequência pouco expressiva.

Observamos nessa sequência palavras-chave relativas a serviços, a presença expressiva das palavras dining, fitness e banquets com ocorrência em todas as áreas estudadas. Dining aparece como palavra mais frequente, ficando a palavra fitness na segunda posição em uma área, na Ásia; na terceira posição em cinco áreas, na África/Oriente Médio, Leste Europeu, América do Norte, Oceania e América do Sul; na quarta posição em duas áreas, na América Central e na Europa Ocidental. Banquets, por sua vez, ocupa a terceira posição em duas áreas, na América Central e na Europa Ocidental; ocupa a quarta posição em cinco áreas, na Ásia, Leste Europeu, América do Norte, Oceania e América do Sul; ocupa a quinta posição apenas na África/Oriente Médio. Interessante observar que há uma predominância de palavras relacionadas à culinária/cozinha seguida de uma palavra relacionada à área de saúde e lazer. O que chama atenção é a alta frequência apresentada pela palavra Internet, que aparece em terceiro lugar em apenas uma área, na Ásia; em todas as outras áreas, ela aparece em segundo lugar por frequência, ficando atrás apenas da palavra dining. Isso pode indicar 
o elevado grau de importância da rede na vida das pessoas nos dias de hoje, não sendo exceção a rede hoteleira; esse dado confirma o resultado da pesquisa global. Palavras relacionadas à área de transporte, como transportation e taxi, com presença pouco expressiva, apareceram na quinta posição em duas áreas apenas, na América do Norte e na Europa Ocidental. O mesmo ocorreu com as palavras coffee, treatments, cuisine, e bath com presença em apenas uma ou duas das áreas estudadas. Por exemplo, a palavra cuisine aparece com algum destaque nas regiões correspondentes à América Central e à Oceania apenas.

A partir das listas do corpus total, destacamos palavras para estudo como mencionado acima; são elas: rooms e bar, relacionadas à estrutura; cuisine e massage, relacionadas a serviços. Selecionamos as 15 combinações mais recorrentes no corpus.

Nessa sequência observamos dois colocados de alta frequência, ou seja, guest e meeting, com o nódulo rooms, o que não apresenta surpresa pelo fato de guest ser uma palavra fundamental dentro do contexto da hotelaria e meeting por ser uma palavra naturalmente presente em ambientes de hotéis de luxo, para formar meeting room, sala de reuniões em português. Na sequência, porém, obsevamos a presença de combinações lexicais que merecem atenção e estudo por trazerem uma variedade de informações relacionadas aos tipos de espaço dentro de um hotel que não são tão comuns.

Temos então, os colocados treatment e function. O primeiro refere-se a uma sala onde o hóspede pode receber diferentes tipos de tratamento, como aplicação de massagens ou cuidados com a pele. A palavra function por sua vez aparece combinada com rooms representando um espaço de eventos, como festas ou reuniões de negócios. As palavras superior, executive, spacious, comfortable, deluxe, e luxurious apresentam uma mescla de luxo e espaço em destaque, um padrão comumente observado em hotéis 4 ou 5 estrelas. Os colocados conference e non-smoking, por sua vez são claros, ou seja, referemse a uma sala utilizada para conferências e quartos onde o fumo não é permitido. Finalmente, dois destaques, combinações lexicais menos frequentes em comparação com as acima destacadas. São elas: steam e locker. A primeira refere-se a um quarto com banho a vapor, um tipo de sauna com calor úmido e temperatura média de 45 graus. A segunda refere-se a uma sala com armários e cadeados para guarda de roupas e apetrechos dos hóspedes. Devido à baixa frequência dessas combinações, são provavelmente estruturas ou serviços pouco comuns em hotéis desse porte.

Nessa sequência observamos o nódulo bar em diversas combinações com destaque inicial para mini, combinação muito comum em hotéis de diferentes classificações. Espaço representado por um bar com bebidas alcoólicas, não alcoólicas, petiscos e às vezes até artigos de toalete. Em seguida, temos lounge, formando lounge bar, espaço mais luxuoso e caro que a média dos bares em hotéis. Restaurant, formando restaurant bar, espaço que serve prioritariamente bebidas, porém com opção de cardápio e refeições. Lobby, formando lobby bar, espaço no lobby do hotel ou num terraço especialmente reservado para seu funcionamento. Pool (side) formando pool (side) bar, um bar na área da piscina e private, formando private bar, sinônimo de minibar, ou 
frigobar em português, instalado no quarto do hotel. Na sequência, observamos juice formando juice bar, espaço para venda de sucos com ausência de bebidas alcoólicas. Brewery formando brewery bar, instalação muito comum na Inglaterra; um hotel conjugado com uma cervejaria (pub); a palavra brewery normalmente sugere produção própria ou local de cerveja que é vendida numa área reservada do hotel. Coffee, formando coffee bar, espaço que vende exclusivamente café, em especial o café expresso, o que difere o lugar dos chamados coffee shops que oferecem alguns pratos rápidos além do café. Wine, formando wine bar, local que serve ou comercializa vinhos. Candy, formando candy bar, espaço dentro do quarto de hóspedes que oferece doces em geral e diferentes tipos de chocolates. Sushi, formando sushi bar, espaço de culinária japonesa. Finalmente, dois destaques: wet e canvas, formando wet bar e canvas bar respectivamente. $\mathrm{O}$ primeiro refere-se a um bar equipado com uma pia, especialmente utilizada para mistura dos drinks e serviço de lavagem e troca rápida de copos, o que representa um diferencial no atendimento. O segundo refere-se a um bar decorado com obras de arte, em especial quadros e pinturas, o que dá ao local um toque de requinte e cultura.

Nessa sequência temos uma série de colocados com o nódulo cuisine que se assemelham; fazem referência à culinária de renome mundial. São elas: Italian e French, formando Italian cuisine e French cuisine e international e first-class, formando international cuisine e first-class cuisine respectivamente.Os quatro colocados são seguidos da palavra local, para formar local cuisine, que indica cozinha típica da região onde o hotel está situado, uma combinação lexical muito comum também no português. A seguir, temos contemporary, formando contemporary cuisine, combinação utilizada para designar atualidade e também qualidade dos produtos utilizados na elaboração dos pratos, uma forma que faz referência mais especificamente à culinária americana. Vemos na sequência, gourmet e exquisite, formando gourmet cuisine e exquisite cuisine respectivamente com significado muito semelhante; ressaltam a excelência, a elegância e o refinamento da cozinha, enfim, a alta qualidade dos pratos servidos no espaço do hotel. A palavra haute formando haute cuisine guarda uma semelhança de significado com os dois colocados anteriores pelo fato de também destacar a alta qualidade da cozinha e sua cuidadosa elaboração, além de fazer referência à culinária francesa.

Os colocados wholesome, seasonal, crafted e farm-to-table também apresentam uma semelhança de sentido entre si. Formam as combinações wholesome cuisine, seasonal cuisine, crafted cuisine e farm-to-table cuisine respectivamente. Todas elas enfatizam a qualidade dos produtos utilizados no preparo dos pratos oferecidos, mas com algumas particularidades. Por exemplo, wholesome destaca o aspecto saudável dos produtos, seasonal destaca a utilização de produtos da época ou o melhor da época na elaboração da comida, crafted destaca a elaboração manual, artesanal dos pratos sem processos mecanizados; finalmente farm-to-table destaca o aproveitamento rápido dos produtos para a elaboração dos pratos, com pouquíssimo tempo de armazenamento antes do uso, o que contribui para o seu frescor. Finalmente, temos zesty, fomando zesty cuisine e winning-award, formando winning-award cuisine, com sentidos bem específicos. $\mathrm{O}$ 
primeiro colocado refere-se a um tipo de comida com sabor acentuado, com adição de temperos, em especial à base de frutos cítricos, o que dá um sabor picante e diferenciado ao prato. O segundo colocado, faz referência a uma cozinha que é premiada, pela reconhecida qualidade que apresenta no mundo da hotelaria.

Nessa sequência observamos o nódulo massage com colocados envolvendo um substantivo mais preposição e um adjetivo. Trata-se de variety of e relaxing, formando variety of massage e relaxing massage, o primeiro indicando tipos diferentes de massagem e o segundo, uma qualidade propriamente dita, relaxante. Um segundo par com o mesmo sentido aparece na sequência. São eles: in-room massage e in-suite massage, referindo-se à aplicação de massagem no quarto de hóspedes. Em seguida, observamos combinações muito específicas. Four hands massage, indicando massagem a quatro mãos, isto é, aplicação feita por dois profissionais massagistas, deep tissue massage, sugerindo uma massagem especificamente muscular e Swedish massage, com sentido semelhante à imediatamente anterior.

Na verdade, deep tissue massage concentra-se nos tecidos conjuntivos e o objetivo maior é corrigir os movimentos e a postura do paciente enquanto Swedish massage visa melhorar a circulação sanguínea e linfática relaxando os músculos em sua área mais superficial. Na sequência, temos os colocados underwater e aromatherapy formando as combinações underwater massage e aromatherapy massage respectivamente; a primeira combinação está relacionada à hidromassagem e a segunda a um tipo de massagem aplicada com utilização de óleos extraídos de plantas aromáticas e medicinais. Em seguida, destacamos um tipo específico de massagem de origem japonesa, expressa pela combinação shiatsu massage, um tipo realizado por meio de pressão dos dedos do massagista sobre diferentes áreas do corpo com o objetivo de manter o bem estar físico e mental do paciente bem como de curar doenças. Temos a seguir, dois colocados que formam combinações semelhantes na aplicação. Trata-se de hot stone massage e hot shells massage.

Há, porém, uma diferença essencial entre as duas. A primeira faz uso de pedras aquecidas como extensão das mãos do massagista para a execução do processo; a segunda utiliza conchas cheias com uma mistura de minerais e algas com água do mar e óleos. Quando esses elementos são combinados dentro da concha, criam uma reação química que produz calor, que dura entre uma e duas horas. Finalmente temos mais uma vez combinações com sentido bastante específico. São elas: pregnancy massage, tailored massage e wine massage. A primeira refere-se a um serviço de massagem oferecido a mulheres hóspedes grávidas que tem a função de melhorar a saúde, diminuir o estresse e aliviar as tensões musculares das futuras mães. Funciona como um complemento aos exames pré-natais. A segunda representa uma aplicação feita de acordo com a necessidade do cliente/hóspede (tailored); há uma variedade de aplicações possíveis aqui. A terceira sugere uma aplicação feita com utilização de vinho e também suco de uva na massagem, o que ajuda a melhorar a aparência da pele e a circulação. 
A partir das listas do corpus por área, também destacamos palavras para estudo; são elas: pool, relacionada à estrutura e treatments, relacionada a serviços. Selecionamos as 10 combinações mais recorrentes no corpus. A palavra pool, presente na área corespondente à África/Oriente Médio e a palavra treatments, presente na área correspondente à Ásia.

Nessa sequência observamos alguns colocados interessantes com o nódulo pool. O primeiro e grande destaque é representado pela combinação swimming pool, forma muito comum em língua inglesa para piscina. Também com destaque, aparecem em seguida, dois colocados que fazem referência à ocupação de espaços dentro do hotel. São eles: indoor e outdoor formando as combinações indoor pool e outdoor pool respectivamente, correspondendo a piscinas cobertas e piscinas descobertas. Na sequência, observamos um colocado bastante específico, infinity, formando a combinação infinity pool, estrutura aparentemente presente apenas em alguns hotéis de luxo. É um tipo de piscina construída de forma a criar uma ilusão ótica que lhe confere a imagem aparente de infinidade.

Uma das quatro paredes é construída num nível inferior em relação às outras, o que gera a impressão de que o volume de água está ligado a um grande rio ou oceano. Outros dois colocados que vemos a seguir em combinação com pool, são toddler e splash, formando toddler pool e splash pool respectivamente; fazem referência a usuários específicos. A primeira combinação representa uma piscina para crianças ainda na primeira infância (toddlers); a segunda, uma piscina com dois ou três pés de profundidade, para usuários que não pretendem nadar, mas apenas se molhar ou se refrescar. Em seguida, observamos uma dupla de colocados muito comuns, com presença expressiva em diferentes áreas, não apenas na rede hoteleira. São eles: olympic e heated, formando as combinações olympic pool e heated pool, respectivamente, exemplos representativos de piscinas de dimensões olímpicas e de piscinas aquecidas.

Os dois últimos destaques são colocados que formam combinações menos comuns com pool. Trata-se de rooftop e private, formando rooftop pool e private pool. A primeira combinação indica uma piscina instalada no topo do edifício do hotel, que propicia uma visão panorâmica da cidade onde se encontra; algumas se assemelham às infinity pools pela ausência de uma das paredes, o que pode dar a impressão aos usuários de uma possível queda ao nadar. $\mathrm{Na}$ verdade, há uma extensão da piscina num nível inferior impossibilitando a ocorrência de acidentes. Esse tipo de piscina é uma atração à parte no ambiente de hotéis de luxo no mundo. A segunda combinação indica uma piscina particular instalada em alguns quartos; estes, normalmente apresentam em sua estrutura uma varanda e acesso para o espaço da piscina, em alguns casos com a presença de um jardim. A estrutura representa um diferencial sofisticado e é encontrada apenas em hotéis muito luxuosos e requintados em certas regiões do globo.

Nessa sequência temos a presença de colocados com sentidos diversos. Os dois primeiros são body e massage, formando as combinações body treatments e massage treatments; segundo o texto, referem-se a terapias e massagens para o corpo. A seguir, 
temos os adjetivos specialized e simple formando as combinações specialized treatments e simple treatments. A primeira, segundo o texto original, refere-se à combinação de tratamentos com propriedades curativas originários da Ásia antiga e receitas de beleza à base de produtos naturais. A segunda, simplesmente faz referência a tipos de tratamentos representados por massagens relaxantes. Em seguida, temos dois adjetivos que fazem referências bastante específicas a tratamentos de beleza. São eles, natural e beautifying, formando as combinações natural treatments e beautifying treatments.

O primeiro, de acordo com o texto, combina tratamentos ocidentais, suíços mais especificamente, com os métodos de tratamento naturais de Bali, na Indonésia; contemplam a beleza e a saúde. O segundo destaca tratamentos de beleza à base de ervas e óleos, cuja aplicação traz benefícios para a pele e a saúde em geral; é originário de Taiwan. Os próximos colocados são top-of-the-line e aesthetic que aparecem numa mesma sequência no texto, formando as combinações top-of-the-line treatments $e$ aesthetic treatments respectivamente. Os tratamentos de primeira linha (top-of-the-line) oferecidos pelo spa do hotel referem-se, segundo o texto, a rituais estéticos e holísticos especializados, ou seja, preocupam-se com o corpo em sua totalidade em detrimento das partes isoladamente, aparentemente algo valorizado em países orientais (o texto em questão é de um hotel em Singapura). Os dois últimos colocados abordados são delightful e beauty, formando as combinações delightful treatments $e$ beauty treatments respectivamente. Elas formam combinações que se assemelham pelo seu sentido corriqueiro; as duas fazem referência a tratamentos básicos de beleza como cuidados com a pele e o cabelo, massagens e serviços de manicure e pedicure.

\section{Conclusões}

A coleta de textos da rede com informações sobre estrutura e serviços hoteleiros mostrou ser de grande utilidade por atender satisfatoriamente aos objetivos a que nos propusemos no início da pesquisa. O corpus de estudo selecionado inicialmente poderá ser realimentado periodicamente, permitindo uma ampliação do volume de léxico e consequentemente novas possibilidades de pesquisa sobre o que a rede hoteleira pode oferecer em diferentes partes do mundo.

A primeira sequência abordada, estrutura e serviços hoteleiros presentes no corpus global, propiciou uma visão mais abrangente da estrutura e dos serviços oferecidos pelos hotéis 4 e 5 estrelas no mundo. Os destaques representados pelas áreas de saúde/lazer e culinária certamente estimulam novas incursões com pesquisas de léxico envolvendo hotéis de diferentes classificações, o que abre campo para estudos comparativos relacionados aos diversos padrões ou níveis de sofisticação da rede hoteleira presente nos oito continentes.

A segunda sequência referente ao estudo lexical de estruturas e serviços por área veio confirmar uma tendência observada na abordagem anterior, global, ou seja, a 
presença expressiva de léxico envolvendo as áreas de saúde e culinária. Veio confirmar também a importância da rede, a internet e suas ferramentas na atualidade. Os serviços mais presentes acima citados, saúde e culinária, tem sua posição ameaçada pela presença da palavra internet, que aparece com alta frequência em todas as áreas pesquisadas. $\mathrm{O}$ fenômeno sugere uma atenção especial dos pesquisadores para a área de sistemas informatizados em uso no ambiente dos hotéis.

A terceira sequência relativa às palavras-chave do corpus total e colocados destacadas para estudo trouxe à tona combinações com significados muito diversificados, em especial aquelas relacionadas à área de serviços com as palavras cuisine e massage. Algumas delas exigiram ampliação do estudo com consultas em diferentes sites presentes na rede para levantamento de significados, parte importante de nossa proposta de pesquisa.

A quarta sequência, relacionada às palavras-chave do corpus por área e colocados destacadas para estudo, (outras farão parte de futuras seleções para pesquisa) propiciou alguns achados interessantes e exigiu também uma ampliação da abordagem como na sequência discutida no parágrafo anterior. Pelo fato de serem combinações lexicais muito gerais, foi necessária uma volta aos textos do banco de dados para levantamento e análise de linhas de concordância, o que permitiu acesso a significados e discussões mais abrangentes e enriquecedoras.

Destacamos mais uma vez que a pesquisa envolve não somente o levantamento e a criação de um corpus de estudo na área de estruturas e serviços oferecidos pelos hotéis, mas também a possibilidade ilimitada de uma recriação ou ampliação desse acervo para estudos linguísticos a qualquer momento, hoje e no futuro. A proposta representa um campo aberto e rico em alternativas; tem à disposição um universo vasto como a rede, importante referência; e o léxico, produto colhido, estudado e utilizado de acordo com as necessidades de pesquisadores, alunos e interessados na área em geral.

\section{Referências Bibliográficas}

ASTON. G. Small and Large Corpora in Language learning. In: Palc Conference,Lodz, University of Lodz, 1997.

BERBER SARDINHA, T. Linguística de Corpus. Barueri: Manole, 2004.

Como usar a Linguística de Corpus no ensino de língua estrangeira. In: Viana, V.; TAGNIN, S. (Orgs.). Corpora no ensino de línguas estrangeiras. São Paulo: HUB Editorial, 2011. p. 302-356, 2004.

CARVAlHO, A. F. Políticas Públicas em Turismo no Brasil. Sociedade e Cultura, v. 3, n. 1 e 2, jan/dez. 2000, p. 97-109, 2000.

CONRAD. S.; DUSICKA. P; PFEIFFER. P. Work in Progress. A new approach for understanding student and workplace writing in engineering. 39th Frontiers in Education Conference. San Antonio, Texas, 2009 
IMBERNÓN, F. Formação docente e Profissional. Formar-se para a mudança e a incerteza. São Paulo: Cortez, 2009.

O'KEEFFE, A e McCARTHY, M. What are corpora and how Have They Evolved? In: O'KEEFFE, A.; M. McCARTHY. (Eds.). The Routledge Handbook of Corpus Linguistics. London/New York: Routledge, 2010

SINCLAIR, J. Corpus, Concordance, Collocation. Oxford: Oxford University Press, 1991.

TRIBBLE, C. What are concordances and how are they used?. In: O'KEEFFE, A.; M. McCARTHY. (Eds.). The Routledge Handbook of Corpus Linguistics. London/New York: Routledge, 2010

José Roberto LOURENÇO is Professor of Business English and English chair responsible for the courses in Secretariat and Tourism at (FATEC-SP). He received his PhD in Applied Linguistics with a focus on Corpus Linguistics from PUC-SP. His interests include educational development in the areas of Business and English. E-mail: jrlourenco@yahoo.com.br. 